\title{
Chronic swelling of the foot
}

\author{
Dyan V. Flores ${ }^{1}$
}

Published online: 29 March 2017

(C) ISS 2017

Test Yourself Question: Chronic swelling of the foot.

Question: A 45-year-old man with four months' history of progressive foot swelling (Figs. 1, 2, 3, 4 and 5).

Images:

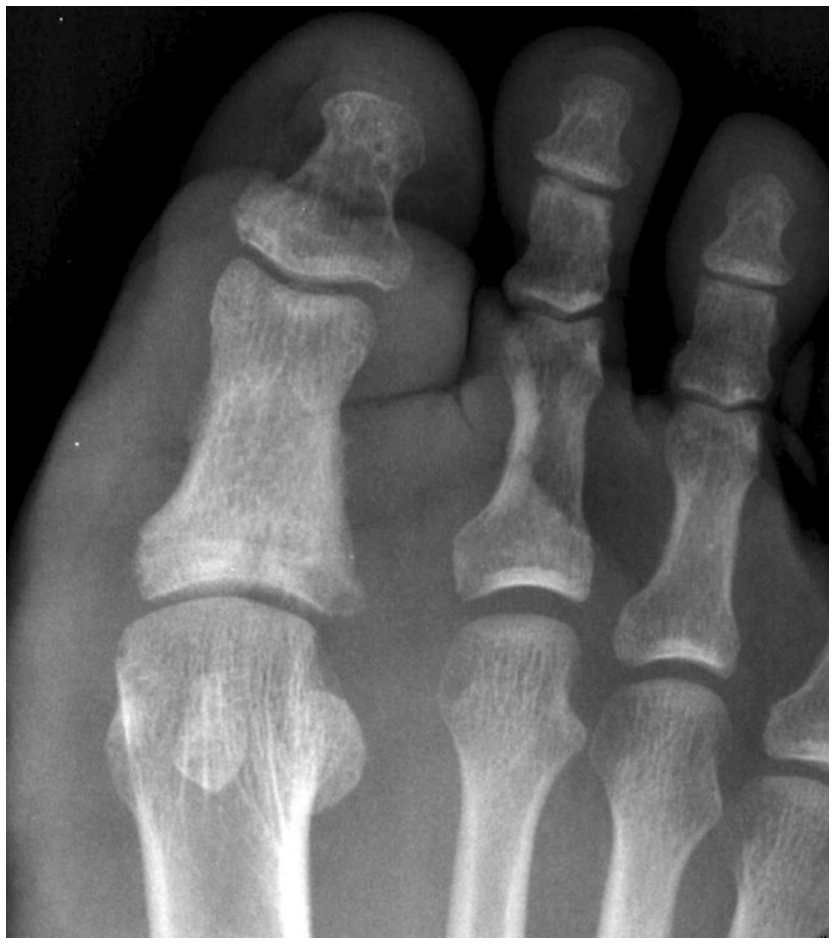

Fig. 1 Radiograph of the great toe

The diagnosis can be found at doi: 10.1007/s00256-017-2641-6

Dyan V. Flores

dyanflores@yahoo.com

1 Department of Radiology, Makati Medical Center, \#2 Amorsolo Street, Legaspi Village, 1229 Makati City, Metro Manila, Philippines
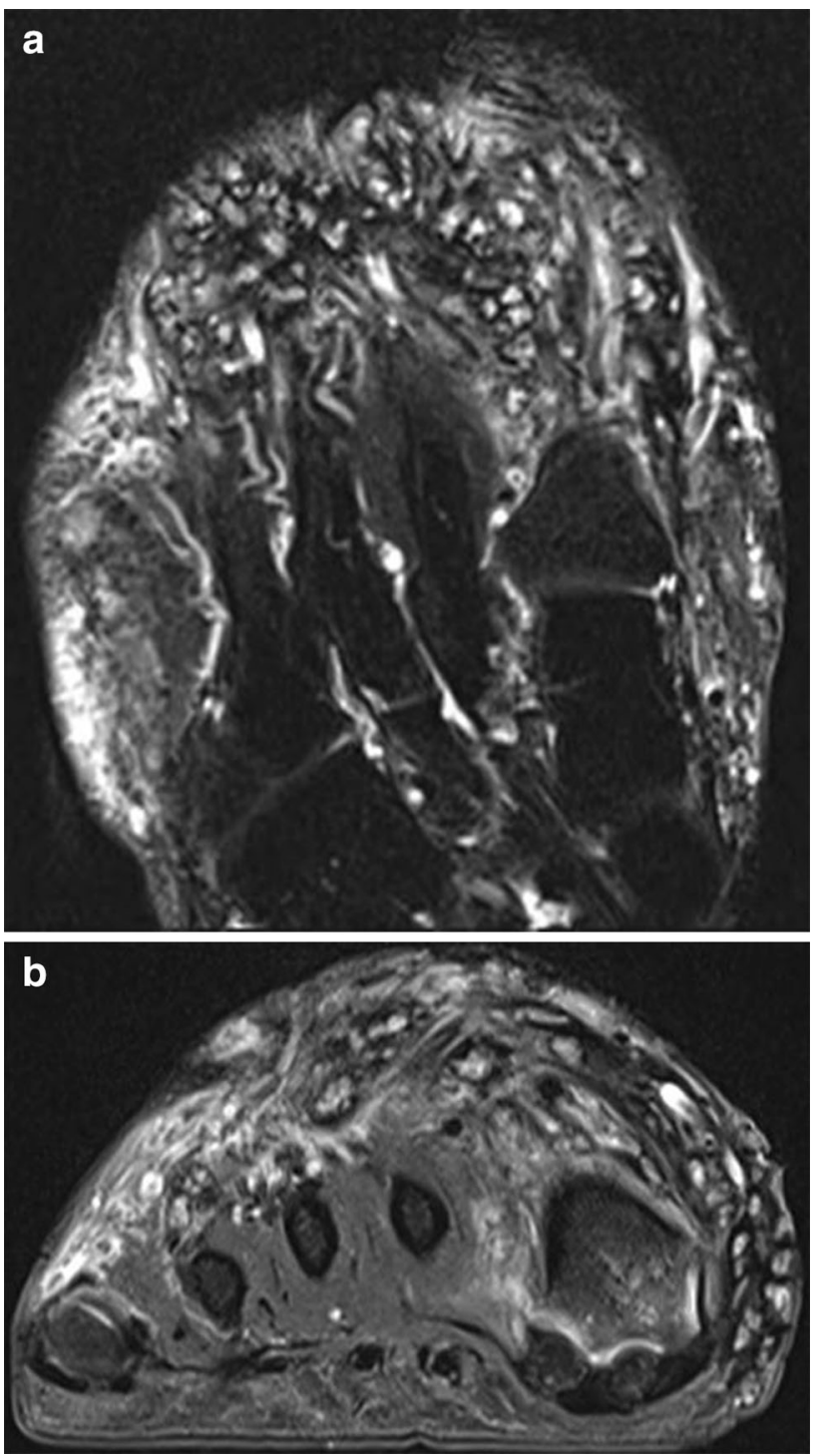

Fig. 2 Axial (a) and coronal (b) T2-weighted fat-suppressed images of the forefoot 

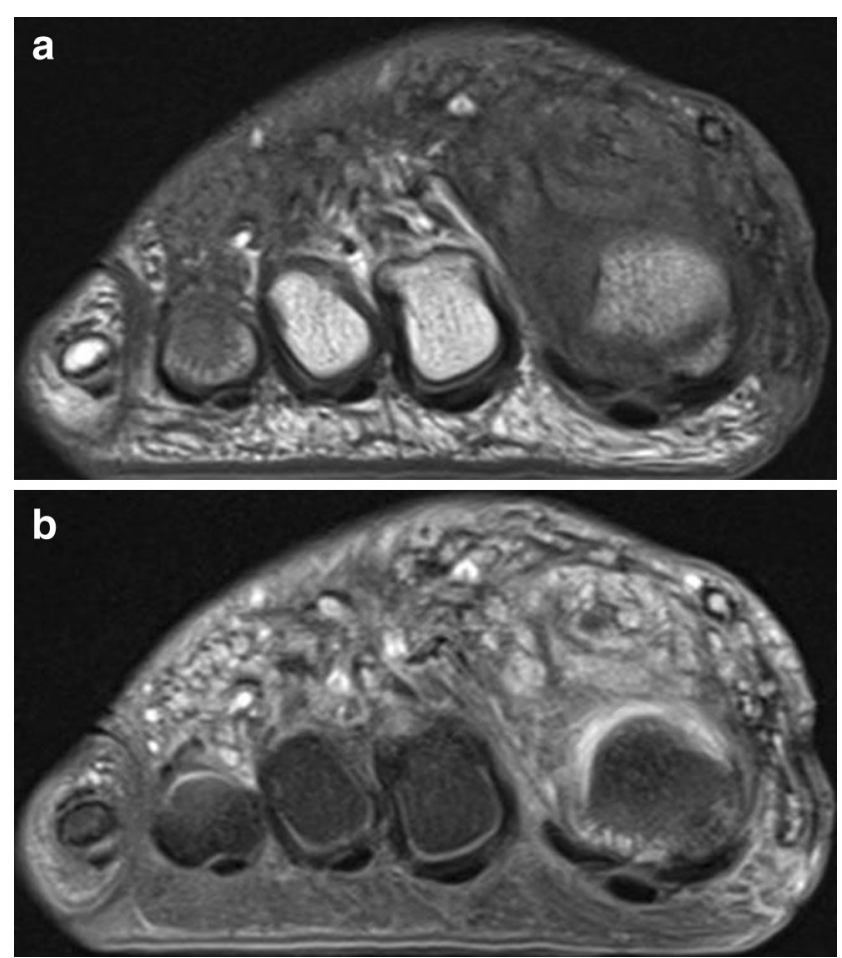

Fig. 3 Coronal T1-weighted (a) and T1-weighted fat-suppressed postcontrast (b) images of the forefoot

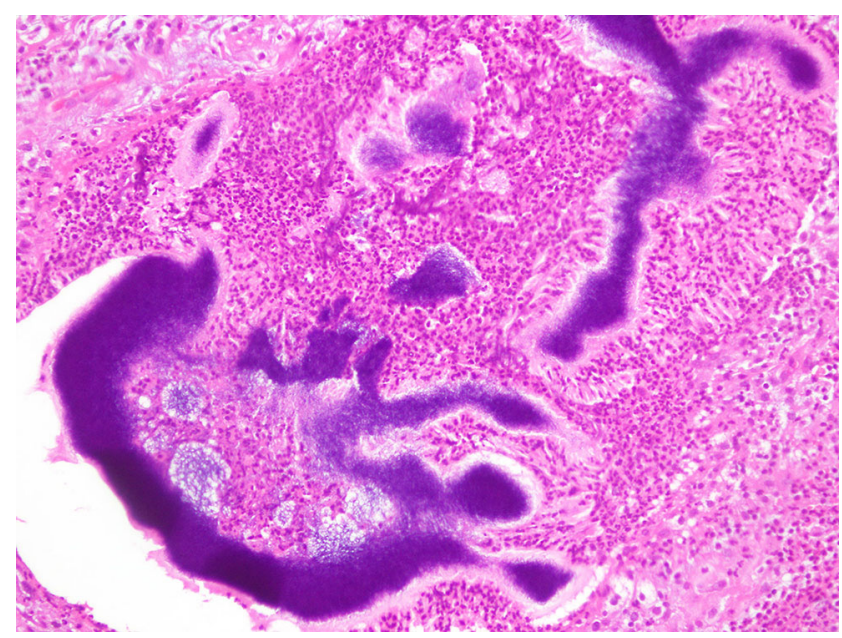

Fig. $5 \mathrm{H}$ and $\mathrm{E}$ stain. 100x

\section{Compliance with ethical standards}

Grants received None.

Disclosures None.

Conflict of interest None.
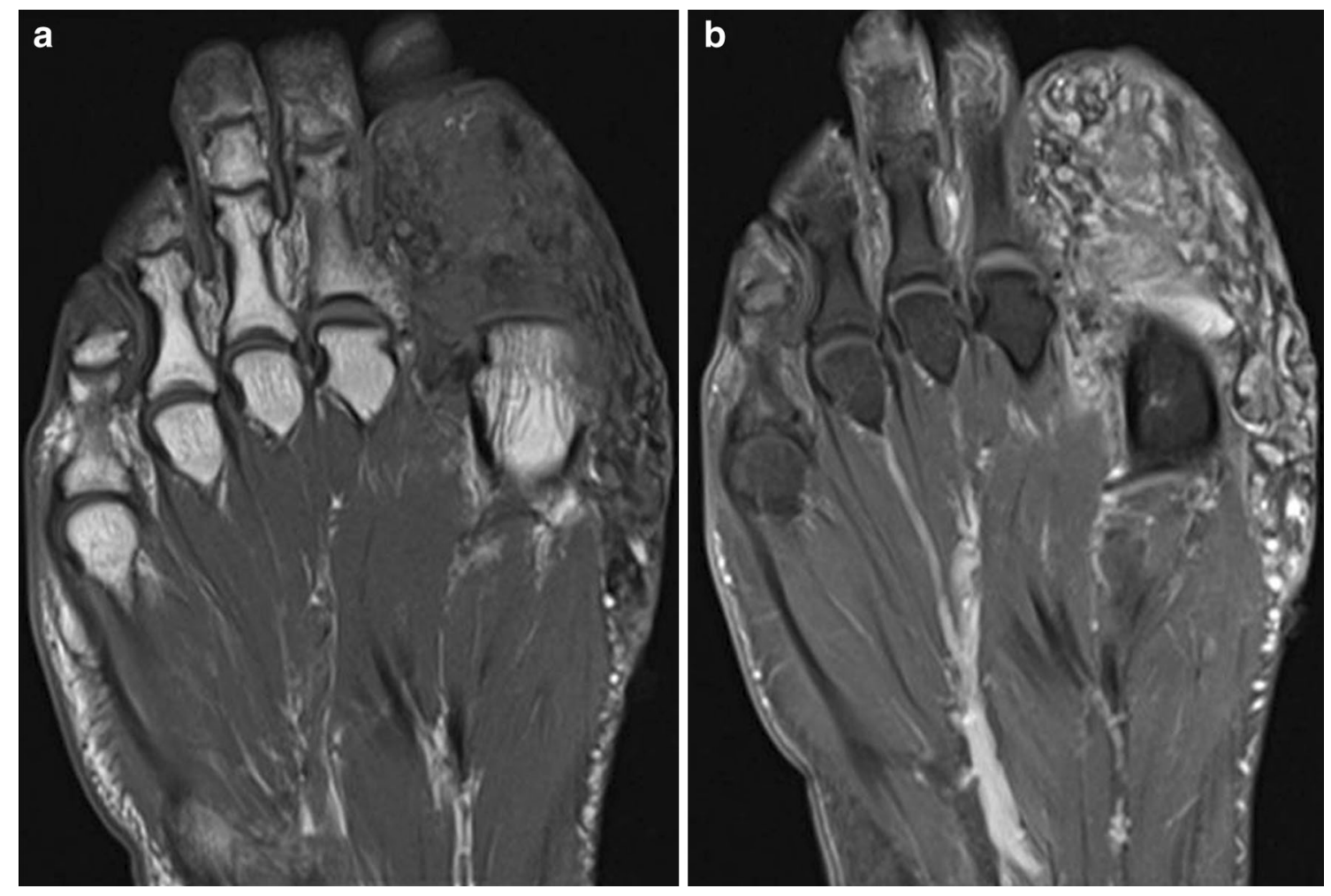

Fig. 4 Axial T1-weighted (a) and T1-weighted fat-suppressed postcontrast (b) images of the forefoot 